\title{
JOSÉ WATANABE, LA ESCRITURA DEL CUERPO EN EL ESPACIO
}

\author{
Carlos Dimeo \\ Universidad de Bielsko-Biala \\ Bielsko-Biala, Polonia \\ cdimeo@ath.bielsko.pl
}

\begin{abstract}
RESUMEN / ABSTRACT
Casi la mayor parte de la poesía de José Watanabe está rodeada por el tema del cuerpo. La idea de corporeidad se presenta en dos áreas: por un lado, el tema de la evanescencia de la vida que muestra un cuerpo disoluto, etéreo o volátil; y por otro, el espejo opuesto a sí mismo, es decir, la existencia persistente del cuerpo como materia presente, como una realidad que ocurre en un tiempo y en un espacio visible. Tomando esto como punto de partida, queremos hacer una revisión temática a través de la obra poética del autor peruano, marcando el énfasis en tres de sus poemarios: Cosas del cuerpo (1999), Antígona (2000) y La piedra alada (2005).
\end{abstract}

PALABRAS CLAVE: cuerpo, subjetividad, poesía dramática, cuerpo ético, metafísica.

\section{JOSÉ WATANABE, THE WRITING OF THE BODY IN SPACE}

Most of José Watanabe'poetry is surrounded by the subject of the body. The idea of corporeality is presented, on the one hand, in the theme of the evanescence of life that shows a dissolute, ethereal, or volatile body; and on the other, in the mirror opposed to itself, that is, the persistent existence of the body as present matter, as a reality that occurs in a time and in a visible space. Taking this as a starting point, we want to make a thematic review through the poetic work of the Peruvian author, marking the emphasis on three of his books: Cosas del cuerpo (1999), Antigona (2000) and La piedra alada (2005).

KEYWORDS: body, subjectivity, dramatic poetry, ethical body, metaphysics.

Recepción: 16/03/2020

Aprobación: 16/03/2021 
La lectura de la poesía y del teatro me han llevado por distintos caminos de la interpretación textual. A partir de allí, ha venido insistiendo sobre mí la idea de que el texto, el texto literario escrito, es también un cuerpo, o cuando menos un tipo de corporalidad. La responsabilidad con que se debe tomar la palabra cuerpo se sustenta en la búsqueda permanente de una materialidad. No obstante, esta materialidad a través de la que el cuerpo aparentemente se manifiesta, se nutre de diferentes sentidos y significados. Dicho de otra forma, todo cuerpo, llámese cosa o no, es materia propia de esa cosa, pero se manifiesta en tanto tal solo a partir de sus significaciones y sus significados y no tanto desde sus significantes. Por ejemplo, una mesa es cuerpo debido a la cosa material de la que está hecha, pero también debido a la significación de la que se puede nutrir.

Ahora bien, en poesía, cuerpo y corporeidad no son en sí mismos representaciones de un algo material, no son un "eso" denotado que a primera vista se ve, sino algo que más bien se aprecia solo a partir de la palabra poética. Lo que la palabra poética llama un "eso" (que es un eso no-material, el eso poético) se refiere a la autenticidad inmanente de la entidad enunciada, de la cosa misma, del cuerpo. La diferencia estriba, en que, por lo común, damos nombre a algo si estamos en presencia directa de esa cosa misma, de una materia que es visible a nosotros. No importa si esta cosa es un cuerpo vivo o un cuerpo inerte. Pensar el cuerpo como algo absolutamente no carente de corporeidad forma parte de una subjetividad que tiene su punto de partida en la modernidad cartesiana. Sin embargo, la filosofía y la poesía, estando en el centro de su propia subjetividad, enuncian la materia a la que pertenecen y desde allí se entroncan con la cosa misma, la cosa en sí. Es esta "indisposición" de la cuestión filosófica y poética (o se es en una, o se es en el otra) la que constantemente coloca a ambas en el plano de la subjetividad.

Comúnmente, poesía y filosofía parecen retroceder ante un mundo que cada vez quiere ser más objetivo y, en consecuencia, no pretenden aferrarse a una explicación de lo material. En todo caso, la poesía lleva una ganancia: no tiene por qué hacer distinción entre mundo objetivo, ciencia, cuerpo visible, materia, y un mundo sensible, ideas, cuerpos eidéticos, etcétera.

Solamente por el hecho de que el cuerpo se ve, se entiende que este es un ente que está allí y que parece ser o que se presenta como tal, cuando en realidad todo cuerpo se constituye no como instancia en sí mismo, pero sí como 
"cosa sida". Es por ello que solo a partir del lenguaje el cuerpo representa a algo más grande que una entidad. De este modo, la palabra "cuerpo" ejecuta un acto denotativo, un enunciado elaborado no desde su significado, sino desde su significante. Y aquello que nombro "cuerpo" solamente es posible como entidad gracias a que es exactamente el lenguaje quien le da orden y sentido. De otro modo, el cuerpo, ese estatuto propio de sí, no es más que un significante y como consecuencia de ello atiende a diversos órdenes, donde uno de ellos es propiamente el de la subjetividad.

La necesidad de representación que surge de ese cuerpo subjetivo pone en alerta al sujeto. Y la poesía atiende a esa doble condición, a la de ser cuerpo como sujeto, y por ende subjetivo, pero también a la de ser cuerpo como objeto. El propio poema adquiere esta complejidad, como texto en un cuerpo interior que se desplaza a lo largo del poema. Ya que al cuerpo se le considera la representación material de una subjetividad, la poesía está allí presente en ese "estar entre". En este sentido, Theodor Adorno, en su libro Kierkegaard (1962), afirma que: "Poesía es para él [Søren Kierkegaard] determinar el comportamiento del poeta, puesto que, ante su melancolía, el mundo objetivo retrocede" (19). De esta manera, Adorno nos explica cómo Kierkegaard nos ha puesto en la dicotomía de un "estar ahí" con el cuerpo, pero, solo si el poeta lo reconoce, es mundo objetivo. El cuerpo de la poesía, el cuerpo poético no es en modo alguno objetivo, sino siempre subjetivo. Esta disyuntiva, en especial hoy en día, donde la "presencia" resulta un apéndice de la vida misma, supone que lo poético es, en tanto texto-cuerpo de la poesía y en tanto metáfora que se refiere desde el cuerpo del poeta, la consumación de una relación compleja: palabra y sentido. El cuerpo actúa en ese doble mecanismo como un monismo y quiere consubstanciar al primero con el segundo.

Esa misma relación o vínculo entre cuerpo y sentido, cuerpo y alma, nos plantea un interrogante en torno a la existencia. Ya en la pregunta por la cosa ("cosa en sí" y “cosa sida”) está implícita la pregunta por la subjetividad y la existencia. Aunque ninguno de los dos posea propiedades en sí que cedan el paso a la determinación de uno por otro, la tarea del filósofo y por ende también del poeta (si lo tomamos como en Nietzsche) radica en lograr separar definitivamente la fuerza de la filosofía sobre la de la poesía (la fuerza del

\footnotetext{
"Cosa sida" se refiere aquí en el sentido filosófico del término en relación con lo "instituido" y "constituido".
} 
cuerpo sobre el alma), del ser sobre la metafísica. Una relación intrínsecamente compleja en la que el primero siempre surge como correlato del segundo.

Todo cuerpo ${ }^{2}$ es una ontogénesis, a partir de lo cual surge la cuestión: ¿En qué momento y cuándo nos constituimos como un cuerpo o cuándo dejamos de serlo? De todas maneras, si tal como afirma Jean-Luc Nancy "nosotros somos el sentido" (Nancy 2003 74), el cuerpo es solamente tal cuando se afirma en el sentido. Y todo cuerpo es en sí, antes que materia, sentido. No obstante, sin todo este carácter solo es posible a través del lenguaje: será el lenguaje el que otorgue al cuerpo su carácter de presencia. Watanabe, públicamente y en diversas ocasiones ha afirmado: "El cuerpo no es más que el sentido" (1989 24). Una afirmación bastante similar a la de Nancy, anunciándonos la dirección precisa del sentido en el cuerpo, lo que para Watanabe sería el cuerpo del sentido. El poema es el sentido porque también es este el que se determina como un cuerpo. En el poema "El maestro de Kung Fu":

Un cuerpo viejo pero trabajado para la pelea

madruga y danza

frente a los arenales de Barranco

Se mueve como dibujando

una rúbrica antigua, con esa gracia, y

sin embargo, está hiriendo, buscando el punto

de muerte

de su enemigo, el aire no, un invisible

de mil años (Watanabe, Poesía 210)

En la filosofía, cuerpo y sujeto son díadas distintas, y ambos pueden presentarse a sí mismos como "entidades". No obstante, del universo de categorías que ha desarrollado el pensamiento filosófico, la del cuerpo parece ser la más precaria. Su carácter recio, su aparente pertenencia al mundo de lo sólido y en cierto modo impenetrable nos muestran siempre que el cuerpo está activo, tal como si fuera un "estar-allí" presente. Pero en muchas ocasiones, aún incluso después de la muerte, sea esta cercana o lejana, el cuerpo sigue haciendo presencia unido consustancialmente a la existencia. El cuerpo es experiencia. Esa propiedad de que lo visible es el cuerpo y de que este puede aparecer en el lugar del otro es el punto de reserva de un dominio y principio que pertenece a la fenomenología. Pero en tanto y en cuanto el cuerpo es 
atacado (aunque sea por una mínima partícula externa), su aparente solidez empieza a desmoronarse y tiende a desaparecer. Por lo tanto, este es un cuerpo enunciado, cuya substantivación se transforma en un tipo de adjetivación. Cuando se dice "el cuerpo", esta voz no marca la aparición de un sustantivo; si se dice: "el cuerpo", esto es, ya en ese instante, una forma adjetivada de la palabra. Lo es, no en tanto valor sintáctico, sino en tanto el sentido que ejerce sobre el otro. Es precisamente el enunciado quien abre una dimensión de sí que muestra una característica esencial de ese "algo" representado en la ejecución de una acción.

En casi toda la poesía de José Watanabe se explora esta forma de adjetivación del cuerpo. El cuerpo (si es un enunciado) empieza por adquirir un sentido a la vez de introspección. De manera que, a veces, el cuerpo y el sujeto se separan, pero en otras ocasiones se fusionan actuando como unidad. La poesía de Watanabe se orienta en ese doble sentido: en la relación objeto-cosa, por un lado, y en el entendido de un cuerpo que se ha instalado en el contexto de su introspección, por el otro. Para Watanabe, se es cuerpo desde afuera, pero también desde adentro.

Su primer poemario, Álbum de familia, fue publicado en 1971. Pero desde este libro hasta su segunda publicación, El huso de la palabra (1989), pasaron dieciocho años de "silencio", que, como el mismo José Watanabe ${ }^{3}$ afirma en una entrevista realizada por Alonso Rabí Do Carmo, "no tuvo conocimiento del porqué no publicó nada, aunque nunca durante este tiempo dejaría de escribir" ("El estilo" 102). Pareciera como si José Watanabe hubiera sido una piedra insular en medio del vasto panorama poético que rodeó a los de su generación (la de los años setenta), aunque no por ello se le consideraría o se le pudiera considerar, en todo caso, una "isla solitaria". En realidad, de ningún modo el poeta estuvo aparte (o apartado) de ese amplio conjunto que bordeó a los dos grupos poéticos más famosos de su época: Hora Zero y Estación Reunida. Aunque de una manera "esporádica y en el último tramo" (De Lima y Guerrero 342), Watanabe efectivamente publicó su poesía y estuvo

\footnotetext{
La obra completa de José Watanabe (1945-2007) está compuesta por las siguientes obras: Álbum de familia (1971); El huso de la palabra (1989); Historia natural (1994); Cosas del cuerpo (1999); Habitó entre nosotros (2002); La piedra alada (2005); Banderas detrás de la niebla (2006). En el año 2005 se publicó la antología de todos sus libros intitulada como Lo que queda, con introducción de Micaela Chirif (Caracas: Monte Ávila Editores) y en el 2008 Poesía completa, con prólogo de Darío Jaramillo Agudelo (Lima/Valencia: El Virrey/ Pre-Textos).
} 
presente en el grupo poético Estación Reunida. Más adelante hay una fuerte presencia y significación del poeta no solo en el grupo, sino expandiéndose hacia toda la poesía peruana. Sobre algunos de los textos de Watanabe en Estación Reunida, De Lima y Guerrero agregan:

En el mismo número [doble (4-5) (mayo-junio de 1968)] de Estación Reunida, José Watanabe publica los poemas "Son las diez y te pregunto" ("Háblame de comarcas que recorrerás nuestros pies,/ inventa calles naciendo de este lecho, convoca/ nuestros muertos suaves y mansos [...] abrázame ahora y construyamos nuestra fuerza. Mañana los recibiremos dispuestos a no perder la contienda") y "Cuatro muchachas alrededor de una manzana" (348).

En la introducción a la antología Lo que queda (2005), Micaela Chirif afirma que ambos grupos fueron "lectores de los canónicos Eliot y Pound, y de la poesía norteamericana posterior a ellos, los beatniks especialmente" (VII). La mención de Chirif enseguida nos lleva a indagar en la ensayística poética de Ezra Pound, pues esta también nos puede ofrecer un punto de partida para comprender esta metaforización total de la palabra que Watanabe acostumbraba a tener. Se aúna a ello el hecho de que los poetas casi contemporáneos a Watanabe también estuvieron influenciados por la poesía de Ezra Pound y T. S. Eliot. En este sentido, Eduardo Chirinos destaca que:

Desde la caracterización de Cevallos, es un lugar común señalar que la poesía peruana (y aún la hispanoamericana) de los años sesenta se nutrió de la poesía de Bertolt Brecht, de la anglosajona y francesa del siglo XX (Eliot y Lowell en Cisneros; Auden y los beatniks en Lauer; Pound y Saint-John Perse en Hinostroza), y que muchos de sus héroes culturales fueron los mismos a quienes leyeron y admiraron sus contemporáneos europeos y norteamericanos (276).

Se trata aquí de la ya canónica asimilación de los poetas mencionados a la tradición de la poesía peruana marcada por influencias de "poetas fuertes" (Bloom 13), que Leonidas Cevallos Mesones demarcó claramente en el famoso libro Los nuevos (Cisneros/Henderson/Hinostroza/Lauer/Martos/Ortega) publicado en 1967 por Editorial Universitaria. De acuerdo con Ricardo Falla, será esta la generación de poetas los que prácticamente introduzcan, entre otros poetas anglosajones, a Ezra Pound, T. S. Eliot, Jack Kerouac y Allen Ginsberg (cit. en De Lima y Guerrero 346). 
Las influencias marcadas por los poetas anglosajones se convertirán en los detonadores de un sinfín de significaciones en el mundo poético del Perú. Los poetas y la generación que analiza, explica y describe Cevallos Mesones están colocados muy cerca de Watanabe y en la misma línea de tiempo. También marca una serie de aspectos que descubren, incluso a un lector avezado, las huellas más profundas de la excelsa poesía peruana. En este juego de metaforizaciones de la palabra, con la que Watanabe se mostró condescendiente, los poetas que aparecen en la edición de Los nuevos también se asocian a ella. Afirma Cevallos Mesones que: "En efecto, algunos de los poetas que sostenían las posiciones más extremas y recalcitrantes se vuelcan de lleno a una poesía lírica de metáforas exuberantes" (8). Lo que se desprende de nuestra lectura de la "presentación" hecha por Cevallos Mesones es que esta generación trascendió la voluntad conquistadora y de recuperación de la palabra que ya habían intentado los "poetas-puros [así como los] poetassociales" (Cevallos Mesones 7), incluso a pesar de lo que pensaba Rodolfo Hinostroza $^{4}$. Será en este marco en el que se va a encontrar José Watanabe, tratando con una palabra que avanza contantemente por las dimensiones del cuerpo ${ }^{5}$ y sus dialogías.

Su poesía, pues, estuvo rodeada, en casi la mayoría de sus textos, por el tema del cuerpo. La idea de corporalidad en Watanabe se debatió en dos ámbitos. Por un lado, el tema de la fugacidad de la vida, mostrando un cuerpo disoluto, disuelto, etéreo o volátil; y, por otro, el espejo contrario al cuerpo como totalidad. Es decir, Watanabe comprendió al cuerpo como la persistente existencia de un sí mismo y también como materia que vive en el presente; realidad que se da en un tiempo y en un espacio "visibles". Esta aparente dicotomía -lo material y lo inmaterial, lo corporal y lo incorpóreoque históricamente ha atravesado a la poesía en general, es retomada por el poeta peruano en distintos libros.

Para Watanabe, lo material no pasa únicamente por el lugar de lo visible. Lo transparente, lo que no se ve, es igual y efectivamente también una materia. Y, aún más, es una materia absolutamente poética -que, por supuesto, al

\footnotetext{
"Rodolfo Hinostroza rechaza la experiencia poética de la generación anterior, en la época de 'la absurda polémica poetas puros-poetas sociales, optó por una tercera posición en la negatividad'. Respecto a los poetas sociales nos dice que después de la muerte de Heraud y la derrota de las guerrillas, 'los poetas tuvieron que conformarse conformarse con ser juzgados por su obra escrita. Un enorme naufragio, quiero decir'” (Cevallos Mesones 10).

Entiéndase el sustantivo "cuerpo" en todas las dimensiones posibles.
} 
ser poética es distinta-. Todo objeto es, pues, solo una prolongación visible y consistente del espíritu y de su esencialismo. Pero la "cosa", la "cosasida", no es solo esto, sino también cuerpo como materia existente y viva. Partiendo de esa premisa, lo poético en Watanabe se desplaza en un solo sentido, va de una "extrospección" hacia una introspección. No obstante, dependiendo de si se trata de una materia "metamorfoseable" o si, por el contrario, es una materia dura que aparentemente no posee movilidad, ni capacidad de transformación, esta estructura presente en casi toda su poesía puede variar consistentemente. Ante ese tránsito dicotómico, un poemario como Cosas del cuerpo es esencialmente distinto y contrario a La piedra alada. De acuerdo con la fenomenología de Bachelard, y si nos remitimos estrictamente a ella, el primero de estos títulos supondría un cuerpo que, como quiera que sea, siempre permanecerá adherido a la tierra, a lo terrestre. Por lo tanto, un cuerpo al que le es dificultoso moverse es pesado. De hecho, la mayoría de las metáforas presentes en este libro son metáforas terrestres. En cambio, el poemario La piedra alada supone en sí misma una esencia paradojal. Pues, aunque la piedra es un objeto duro, que rara vez se mueve o expresa algún tipo de voluntad propia, es también (en el libro de Watanabe) un objeto liviano y por lo tanto le está permitido separarse de su origen terrestre. La dicotomía tierra/aire se percibe rápidamente en sus títulos: el primero habla de cosas, el segundo del vuelo. A este deseo del "vuelo", del poeta volador, se le inmiscuyen las resistencias terrestres. La casa es un cuerpo que a veces le resulta ajeno y distante. Otras veces, se acerca al poeta en un doble sentido y su cuerpo es también la casa. De esta manera, Watanabe nos está remitiendo nuevamente a la poética de Bachelard. En La poética del espacio, Bachelard habla del escritor francés Henri Bosco, a través de su novela El anticuario, para explicar el sentido con que Bosco se instituye como poeta espacial: "Así, la casa evocada por Bosco va de la tierra al cielo. Tiene la verticalidad de la torre que se eleva de las profundidades más terrestres y acuáticas hasta la morada de un alma que cree en el cielo" (Bachelard, La poética del espacio 43). Queda claro, entonces, que todo cuerpo sólido (piedra o casa) es un símbolo telúrico que nos ofrece resistencias. Watanabe ha conjuntado distintas visiones de ese lugar absolutamente iniciático: la casa. Pero la casa no es solo la morada, o el "refugio" del ser (Bachelard). Para el poeta, la casa de la que nos habla está representada por su cuerpo. El cuerpo es así el representante máximo en donde "habita" el ser. De otra forma, su cuerpo es una casa. 
El poema está preguntando por "su casa", pero nos habla del cuerpo, no se refiere a la madre, al origen, no usa metáforas terrestres, es un cuerpo alado que se separa del territorio al que estamos profundamente adheridos desde la niñez: la casa como cuerpo, la madre como origen del cuerpo del otro. A Watanabe le interesa explorar el cuerpo no solo como presencia de lo erótico y lo dinámico, sino también como morada. No es la casa como espacio, es el cuerpo como lugar que habitamos perennemente, del que nunca nos separamos. Es desde allí que el poeta toma como punto de inicio, para sus poemas y para toda la construcción poética de su obra, el hallarse entre el ser como espíritu metafísico y el cuerpo. El siguiente ejemplo es una muestra palpable de ello:

\section{Mi casa}

Mi vecino

estira su casa como un tejido que le ajusta.

No debería burlarme, si yo mismo inmensamente pegado a mi casa, tanto que a veces las paredes tienen manchas de mi sangre o mi grasa.

Sí, mi casa es biológica. En el aire hay un latido suave, un pulso que con los años se ha concertado con el mío.

Mi casa es membranosa y viva, pero no es asunto uterino. Estoy hablando del lugar de mi cuerpo que he construido, como el pájaro aquel, con baba

y donde espacio y función intercambian carne.

Afuera soy, como todos, del trabajo y la economía, aquí de mi cuerpo desnudo $\mathrm{y}$, a veces, de una mujer que se aviene a ser, como yo, otro órgano dentro de este pulposo tercer piso (Watanabe, Cosas del cuerpo 82) 
Como se puede ver, el cuerpo es también una morada en la que habitamos desde siempre y para siempre. "Mi casa es membranosa y viva" (ibid.), y al mismo tiempo representa nuestra concepción del mundo y de la vida, "no es asunto/ uterino. Estoy hablando del lugar de mi cuerpo que he construido" (ibid.). El poeta aclara que no se refiere a la madre, al contrario, el cuerpo es parte de una mirada personal. Las imágenes se reiteran a lo largo de otros poemas: "Mi casa", "Cielo de hospital" o "La ranita" condensan las sutilezas del cuerpo femenino, el cuerpo amante, el cuerpo erótico o también el de la madre y, consecutivamente, el de la casa, todas metáforas terrestres a las que Watanabe responde con las metáforas de un "poeta alado". Así, en "Cielo de hospital" encontramos: "Mi útero de humo sale por la chimenea y se disuelve como nimbo" (Watanabe, Poesía 201). Y más adelante: "Mi útero debió irse como un globo festivo lleno de novios y nonatos" (ibid.).

En el poema "La ranita" aparece el cuerpo femenino demostrándonos su erotismo. El poeta parado frente a la mujer con la que recién ha hecho el amor y duerme, descansa complacida. Estamos ante lo humano hallado en el lugar de los sentidos, en las sensaciones. Este es un cuerpo que nos devela las sensaciones percibidas. allí Watanabe nos descubre a su ser más interior, más profundo. El poeta escribe:

Duermes, mi complacida. Y veo

con qué perfección, equidistancia y malicia

se disponen en tu cuerpo tendido

tus yemas de gusto

concupiscente.

Ahora tus yemas están dormidas, pero cuando están despiertan provocan muchas ocurrencias.

La que más provoca es tu ranita lúbrica

llamada clítoris (ibid.).

Cada poemario de Watanabe significa un arte poética. El poeta convirtiendo su cuerpo en su poesía o tal vez, al contrario, su poesía en cuerpo, el texto llega a adquirir la percepción de un mundo que se muestra con sentido kantiano. Nos referimos al orden perpetuo y a la colocación de este en el purismo del lenguaje. Debemos recordar que, cuando discute con Ernst Cassirer sobre el tema de la naturaleza en Kant, Martin Heidegger afirma que: "para Kant, la 
naturaleza no es una región del ente. Naturaleza no significa jamás en Kant objeto de la ciencia matemática natural, sino que el ente de la naturaleza es el ente del sentido anterior" (214). Esta aclaración es importante porque debemos recordar que, la fenomenología no atiende a lo que la "cosa" posee de suyo, mostrándose como si fuera una "naturaleza" o una esencia. Desde ese sentido, el cuerpo - esa cuestión que denominamos "cuerpo"- no es, en tanto expresión propia de su condición, una naturaleza entendida como "ente" de la cosa. Como se deduce de las propias palabras del autor alemán, la "cosa" ni siquiera es "cosa" porque conlleve en su seno una naturaleza. De hecho, ser cosa no depende de la naturaleza del "sí". No lo es, en tanto y en cuanto el ente siempre es un anterior a la naturaleza misma y por lo tanto a la "cosa". Dicho de otra forma, ente y cosa son distintos.

En el centro de esta reducción casi absoluta, podríamos pensar que la poesía tampoco es una materia, o cuando menos una "cosa", una naturaleza. Y si, tal como afirma Heidegger, la naturaleza no es sino el sentido anterior del ente, el "sentido primigenio" ( ibid.) - o, en todo caso, el sentido primario y originario de ese ente-, en consecuencia, se nos referirá a una poesía que atiende expresamente a la valoración del cuerpo, o que ella misma sea, vaya a ser, cuerpo primigenio de su "oralidad" pero no ente poético. La poesía y su cuerpo son diferentes. La poesía surge pues como modo anterior, es decir, antes que la naturaleza. Y, como agregado, el hecho poético llega a ser la búsqueda de la palabra en la palabra misma, no tanto por su esencia, sino por su origen. En este orden de ideas, se puede afirmar que la palabra es también un cuerpo, pero la poesía, al modo de la cosa que está antes del ente, nos afirma que palabra y cuerpo van unidas y separadas. Todo cuerpo, por sólido o impenetrable que sea, es metamorfoseable y con el paso del tiempo se transforma. Mientras que lo esencial poético es invariable y siempre se mantiene intacto ante el poema. El poema es una "categoría fundamental": el texto poético es el cuerpo de lo poético. Lo poético es una unidad, la palabra en la poesía es una multiplicidad.

Aunque la poesía de Watanabe no intente presumir de esencialista, debido al tono íntimo conversacional que adquiere, vuelve su mirada a esa perspicaz austeridad con que toma el manejo del lenguaje. En este sentido, en la última estrofa del poema "Piedra de cocina", del libro La piedra alada, Watanabe nos deja entrever:

Esta noche distinguí en la cocina al canto rodado negro. Era 
un pequeño animal que se abrazaba fuertemente a sí mismo o se devoraba hacia adentro.

No era la piedra dura que golpea el lomo del cuchillo y destaza

los animales de la comida.

Yo la oí llorar, y era blandita (Watanabe, La piedra 116)

Al final del poema, la piedra, que indefectiblemente actúa y aparentemente es un cuerpo duro, deja de serlo porque empieza a adquirir capacidad de transformación, volviéndose de pronto "un pequeño animal" (tal vez un armiño), aunque nunca perdiendo su esencia de piedra. La revelación de este misterio hace suponer que el autor está consagrado al principio de encontrar la materialización de una esencia que se halla arraigada en lo más profundo del cuerpo con el que se topa. Aunque la piedra no nos deja mirar su fondo, su centro, si el poeta tiene la capacidad de transformarla, ese hecho singular nos permitiría acceder, llegar, y/o mostrarnos el inconsciente del escribiente. En muchísimos pasajes de su filosofía, Bachelard ha aludido a la capacidad de los poetas para conectarnos con su universo inconsciente, característico del análisis ${ }^{6}$.

La poesía moderna ${ }^{7}$ ha dejado de constituirse en una voz superior y prontamente ha empezado a mostrarse como algo que tiene la propiedad de transformar, "domesticar" al objeto, pretendiendo dominarlo desde cualquier perspectiva. Bachelard, al respecto de este tema, afirma que:

No acabaríamos nunca si nos dejáramos llevar por todos los ensueños de la piedra habitada. Curiosamente, dichos ensueños son largos y breves. Se les puede perseguir sin fin y, sin embargo, la reflexión los detiene de súbito. La concha se humaniza al menor signo y, sin embargo, sabemos que la concha no es humana (La poética del espacio 55).

Sin que ello signifique una descalificación a la poesía, en este punto se debe decir que esta es también anterior al cuerpo mismo y que aparentemente siempre lo será. De tal forma que lo esencial de la poesía escrita por el poeta peruano cubre, permea un territorio que permitirá comprender a la palabra 
poética como un lugar donde se puede llegar a crear otro cuerpo de naturaleza diferente. Esta otra materia surgiría así en realidad del cuerpo natural real, del cuerpo visible; el del poeta y no el de la naturaleza o la "cosa en sí". Así que el centro de su "existencia" no está en encontrar la esencia de las cosas, sino en aquello que es sensiblemente vital, en el hallazgo de su substancia.

Pasemos ahora a observar dos materialidades que son persistentemente consustanciales y procedimentales dentro de la poesía de José Watanabe. La primera materialidad de la que hablamos se refiere a la incrustación de dos implementos dramático-escénicos y absolutamente teatrales, que a su vez se ejecutan junto a un tercero, siendo los primeros complementarios de su secuencia y el último actuando de modo independiente, aunque unido a los demás. Estos fueron propuestos por el dramaturgo y director de teatro alemán Bertolt Brecht. Los dos primeros son Verfremdung y Entfremdung. Ambas categorías se traducen en español, respectivamente, como distanciamiento y extrañamiento. La diferencia estriba en que la primera ocurre cuando me distancio de algo conocido, mientras que, en el segundo caso, sufro un distanciamiento después de conocer algo en profundidad. A su vez, ambas categorías parecen acoplarse bajo el concepto de alienación. Por otra parte, Brecht expone una tercera categoría: la "función didáctica de la obra", que está sustentada en la fuente del poema. La segunda de las materialidades se refiere a la llamada "analítica kantiana" (Derrida 48), entendida como una "fenomenología trascendental [que] es una analítica de constitución" (ibid.).

En el primer caso, la fenomenología material-siguiendo a Bachelard-que porta la poesía de Watanabe, le permite librarse de la obligación de concertar una relación estrictamente metafísica con el lector. Puesto que esta no es una poesía del sí mismo y para el sí mismo, el poeta se desplaza hasta el otro (quien lee o mira el poema) con cierta fluidez líquida, pero sin abandonar las premuras que el cuerpo posee y exige. Estos desplazamientos constituyen la fuerza poética que el texto conlleva desde su origen.

Watanabe supo que la fuerza de su voz empezaba en él mismo, a partir de su "relato interior", pero también que esa fuerza de descubrimiento se poetizaba cuando continuaba en el otro. De manera que el poema puede ser un "medio para". Hablar sobre el volumen de la palabra es ubicarse en el centro de una poesía que, como la de Watanabe, busca la totalidad. Así que solo cuando la imagen se completa el texto mismo es la representación, no de un mundo de sensaciones, sino de la eventual existencia física que mira cada vez más hacia las cosas y los objetos. 
Lo anecdótico en su poesía no se significa como mero relato del acontecimiento. El primer juego es utilizado para evocar la distancia, el segundo para acercarnos una intimidad total. De manera que dentro de este "desplazamiento textual", Watanabe produce a la vez el efecto de extrañamiento, acto seguido el de acercamiento, rematando el final con una síntesis que cubriría la llamada función didáctica brechtiana, con lo cual el poema va de afuera hacia adentro y cierra con una conclusión que funciona, en muchos casos, a modo de parábola. El poema "En el ojo de agua" podrá visualizar este aspecto:

Era

un ojo de agua, una lagunilla

de donde bebíamos

gentes y caballos. La luz

no entraba en el agua, la oscuridad que venía del fondo

era más poderosa. Los niños

nos acuclillábamos en su borde redondo

y esperábamos

los pobres envíos de lo insondable.

En sus orillas había una respiración, la cadencia

de un animal muy remoto, un dios mudo

que desde su profundo lecho

mantenía la vida de todos nosotros.

Del fondo afloraban restos de algas, insectos abisales

que nadie podía cazar, pajitas, líquenes

pero todo era indescifrable.

En realidad no esperábamos nada, sólo el placer

de estar en el borde, no sabiendo nada claro,

[imprecisos

$\mathrm{y}$ un poquito idiotas.

A los cincuenta años

ya sabes que ningún dios te va a hablar claramente.

En el viejo ojo de agua

esta vez tampoco hay imágenes definitivas.

Aquí abandona tu arrogante lucidez

y bebe (Watanabe, Poesía 223) 
De esta forma la estructura es: "Era/ un ojo de agua, una lagunilla/ de donde bebíamos/ gentes y caballos" (esto es el afuera, en alemán, el Verfremdung). "La luz/ no entraba en el agua, la oscuridad que venía del fondo/ era más poderosa" (esto es el adentro: Entfremdung). Finalmente, el cierre de la primera estrofa aplica esta función didáctica: "Los niños/ nos acuclillábamos en su borde redondo/ y esperábamos/ los pobres envíos de lo insondable". Lo que Watanabe ha hecho se puede resumir de la siguiente forma: los tres versos iniciales de la primera estrofa nos traen hacia una imagen de la distancia y de la lejanía. Esta sensación no solo penetra en nosotros en tiempo y espacio, sino también a través de las formas expresivas que quiere darnos. No estamos en el mundo de los sentidos, estamos en el mundo de la realidad más corpórea. Vemos el agua, la gente y los caballos, y vemos los cuerpos de los niños inclinándose en el estanque y, más en concreto, se puede ver al poeta mismo en el transcurrir de su vida durante la infancia. El poeta nos coloca, pues, ante una suerte de anécdota de la memoria, comparable in extremis a la que utilizan los narradores en el teatro de influencia brechtiana ${ }^{8}$.

Así, "En el ojo de agua" es un poema que habla del cuerpo, pero lo hace en un tono "menor", revelando, haciendo visible, lo que en realidad es invisible, lo que está en la distancia del tiempo. Tal como explica Fernanda García Lao: "Leer su Poesía completa nos enfrenta a su manera particular, un modo físico, de mirar el mundo. Porque Watanabe no solo ve, vuelve táctiles las palabras" (párr. 3) $)^{9}$.

La segunda parte de esta estrofa es evidentemente una descripción simple del cuerpo en el espacio, de sus posiciones, sus desplazamientos y su inclinación. Pero, al final de este tramo, sorpresivamente Watanabe pasa de una descripción minimalista, esencialista y llana-que confiesa la intimidad de su vida en Laredo- a lo metafórico oculto y profundo, lo lejano que se esconde en el centro de la imagen: "los pobres envíos de lo insondable". Tal como se puede apreciar aquí, el poeta nos conduce desde una imagen material (el agua, la lagunilla, gentes, caballos) hacia una imagen traída como ensoñación de la imagen misma y, por ende, "recuerdo inconsciente" de lo inmaterial.

\footnotetext{
Nos referimos al teatro brechtiano no solo para mencionar a Bertolt Brecht, sino también a otros que utilizaron esta técnica dentro de sus obras, tales como: Peter Weiss, Peter Hacks, Erwin Piscator, etcétera.

Las cursivas son nuestras.
} 
Hagamos un breve alto y detengámonos por un momento en el sentido de la palabra insondable. Según la Real Academia Española, lo insondable es algo que no se puede sondear, algo que está en las profundidades marinas y que ni siquiera con sondas se puede hallar (párr. 1-2). Entonces, de acuerdo con esta acepción podríamos fácilmente pensar que la imagen parte del mundo de lo superficial, de lo cotidiano, y se desplaza hacia la reflexión honda, intocable, que yace en lo profundo, tanto de lo material como de lo inmaterial, del mundo físico y de lo incorpóreo, del cuerpo visible y de un cuerpo que se vuelve invisible y que, como tal, también es cuerpo, si bien inasible, intocable. Probablemente estemos ante la constatación de que el cuerpo que se ve no es el cuerpo que se siente, no es el cuerpo que se vive. La propia realidad de vida que el autor tuvo que soportar, el duro trecho que conlleva toda enfermedad ${ }^{10}$, le obligaron a reflexionar de otra manera sobre las necesidades que el cuerpo debe acarrear durante la vida. En un poema anterior, Watanabe nos habla de un cuerpo puro, beneficiado por el ambiente y la naturaleza que, a su vez, es en sí misma ingenua y límpida, transparente: el niño inclinado bebiendo agua de un estanque a plena luz del día y vinculándose con un mundo de ensueños, con el universo infantil. A pesar de que la metáfora nos retrotrae a una cierta vivificación de lo íntimo, el poeta está situado a una distancia "histórica" que lo muestra profundamente lejana de ella. Al fondo, junto a ese pequeño "bote", adonde "niños caballos y gentes" abrevan el agua, en la profundidad, ese "manantial", que en la superficie es limpio, se vuelve oscuro -probablemente porque el agua está llena de "bichitos" y "pajita" y la luz no logra penetrarla-. Así, la oscuridad del agua no es un símbolo de algo derruido, sino más bien la representación de una infancia en la que la ingenuidad no le permite aún ver el fondo de su inconsciente, todavía oscuro para el niño. Durante el periodo inicial de la infancia, el cuerpo no sabe, no tiene conocimiento ni identificación con su pasado, no lo reconoce, por lo que cuando el niño juega a mirarse en el reflejo del estanque se divierte creyendo que es igual a un espejo. El cuerpo del niño es translúcido y el reflejo de su conciencia es solo una débil señal principiante de la vida. Sin embargo, tal como afirma Bachelard: "Narciso en la fuente no está entregado tan solo a la contemplación de sí mismo. Su propia imagen es el centro del mundo" (Bachelard, El agua 44). En la adultez, en cambio, ese cuerpo está revestido de muchas profundidades psicológicas y de un inconsciente ya

10 José Watanabe sufrió de cáncer, enfermedad que lo condujo muy tempranamente a su desaparición física. 
"desgastado" en el que se pierde la "transparencia" del infante. El juego que antes era fuente de crecimiento, ahora el poeta lo ha olvidado:

A los cincuenta años

ya sabes que ningún dios te va a hablar claramente.

En el viejo ojo de agua

esta vez tampoco hay imágenes definitivas.

Aquí abandona tu arrogante lucidez

y bebe (Watanabe, Poesía 223)

Pasemos ahora a una idea de Bachelard, que puede explicar mejor el funcionamiento interno de este poema:

Aquel que conoce ese reposo concreto en el que alma y cuerpo se bañan en la tranquilidad de la ensoñación comprende la verdad de la paradoja enunciada por George Sand, quien decía: "Los días están hechos para descansar de nuestras noches, es decir, las ensoñaciones del día lúcido están hechas para que descansemos de nuestros sueños nocturnos ${ }^{11}$. Porque el descanso del sueño solo descansa al cuerpo (Bachelard, La poética de la ensoñación 101).

Aunque en el poema de Watanabe el sueño diurno no es el hecho negado del sueño nocturno, hay en la intencionalidad profunda del texto un deseo oculto de descanso. El cuerpo infantil, el cuerpo de la infancia, es un cuerpo que está liberado del reposo porque no está cansado. En los versos de la segunda estrofa eso es más claro aún, pero advirtamos que nuestro cuerpo empieza a funcionar más lentamente, junto con el del narrador:

En sus orillas había una respiración, la cadencia de un animal muy remoto, un dios mudo que desde su profundo lecho mantenía la vida de todos nosotros (Watanabe, Poesía 223)

11 A esta cita, Bachelard agrega lo siguiente: “Ernest la Jeunesse [...] decía: 'Dormir es la más fatigante de las funciones. La ensoñación asimila las pesadillas de la noche. Constituye el psicoanálisis natural de nuestros dramas nocturnos, de nuestros dramas inconscientes" ( $L a$ poética de la ensoñación 101). 
La infancia ha quedado atrás, ya casi sin el aliento de la niñez que no regresa. Es la imagen de la infancia perdida, la infancia acabada o cuando menos en transición, la imagen de un cuerpo que está transformándose, primero en el verso que dice "en sus orillas había una respiración" y más adelante complementándolo con "la cadencia de un animal muy remoto". Quedan, por supuesto, la memoria y el recuerdo de esa simplicidad, pero el final del segundo verso, el tercero y sucesivamente el cuarto, nos marcan el tránsito del tiempo y nos describen el cuerpo ya transformado: "En sus orillas había una respiración, la cadencia/ de un animal muy remoto". El cuerpo infantil se mueve y se desplaza con agilidad, se agacha rápidamente; el cuerpo que va en el tiempo evoca el recuerdo para saber cómo era "la cadencia/ de un animal muy remoto". "Animal remoto" está conectado inmediatamente con la imagen del "dios mudo/ que desde su profundo lecho/ mantenía la vida de todos nosotros". Esto es, a nuestro juicio, la reminiscencia de la vida en la familia pobre, de Laredo, pero además la creencia en ausencia. Estamos ante una especie de vergüenza oculta que surge junto con la sencillez del lenguaje y de las ideas, y también en el preciosismo y la musicalidad de las palabras. Dice Watanabe:

Yo he nacido en un pueblo muy pequeño, Laredo. No tenía mayores aspiraciones y yo pensaba que mi destino iba a ser quedarme a trabajar en el ingenio azucarero. Es decir, terminada la primaria, que era el tope de escolaridad en Laredo, iba a convertirme paulatinamente en obrero (cit. en Rabí do Carmo 103).

Después de que el azar llega a su familia -su padre saca la lotería y eso les permite cambiar de vida y de rutinas-padre, madre, hermanos y el propio Watanabe se trasladan a vivir en Lima, la capital de Perú. Tal como él mismo afirma, será aquí donde empieza a escribir poesía cuando apenas todavía estudiaba la secundaria, lo importante es que el universo limeño donde vive no es un "escenario" para su escritura. Watanabe no "ve" el espacio de Lima como un lugar propicio para sus textos y solo Laredo, "su Comala", será el punto de encuentro entre las cosas (los cuerpos) y sus textos poéticos:

\section{¿Laredo es algo así como tu Comala personal?}

Sí claro, es mi Comala. Sí, es una Comala. Y como toda Comala es también un artificio literario. Es cierto que yo soy un poeta más o menos naturalista y escribo casi siempre lo que veo. Se dice que soy un poeta sabio, pero la sabiduría no está en mí, sino que lo veo 
afuera. Ahora, muchas veces veo cosas en Lima, pero no encuentro la escenografía adecuada para el poema. Entonces, la escenografía la busco en Laredo. Para eso me sirve Laredo, para ambientar muchos de los poemas que escribo (Watanabe cit. en Rabí do Carmo 104).

Watanabe ha asumido aquí la responsabilidad como poeta y como hombre. La responsabilidad de la poesía estriba, según lo afirmaba el propio autor, en la acción de la escritura como objeto privado y como objeto hacia el mundo. El poeta es responsable solo en el instante de la escritura y en el sentido de la trascendencia que esta escritura pueda tener. Sobre la responsabilidad del poeta ante la poesía y el porqué de su escritura, Watanabe decía: "Si yo no escribiera los poemas que escribo, sean buenos o malos, el mundo no los tendría. Lo que quiero decir es que, en todo caso, mi responsabilidad es entregar al mundo un objeto pretendidamente bello" (cit. en Rabí do Carmo 98-99).

En el poema "Mi casa", del libro Cosas del cuerpo (1999), la casa aparece como aquel símbolo que restituye los valores iniciales a partir de una "materialidad original". Si de manera inmediata nos remitimos al análisis que Jacques Lacan propuso sobre la fase del "estadio del espejo" 12 , podemos asumir que la "persona" es "cuerpo" solo cuando se integra como totalidad a partir del momento en que se mira por primera vez frente al espejo y se da cuenta de que es un "todo".

Haciendo una especie de paralelismo, entendemos que el poeta surge de la constitución de la palabra, de tal manera que la palabra también es un cuerpo, en tanto que el poema es su representación. Y así como mirarse al espejo por primera vez e identificarse como una totalidad es también una constitución, de la misma manera el texto poético integra una totalidad desde el momento en que la escritura ha procedido: "mi responsabilidad es entregar al mundo un objeto pretendidamente bello" (Watanabe cit. en Rabí do Carmo 99). Un cuerpo poético que tomó dieciocho años de profunda reflexión.

En la fenomenología de Bachelard, en especial si nos referimos a su libro La poética del espacio, la existencia del poema parte no del escritor mismo, sino de su materialidad poética. Nos referimos a que el poeta, el "poeta

12 La referencia de Lacan parte de la lectura del texto "El estadio del espejo como formador de la función del yo [je] tal como se os revela en la experiencia psicoanalítica", que se publicó en Escritos 1 (pp. 99-105) en Siglo XXI Editores. Antes de publicarse se presentó en forma de conferencia en el XVI Congreso Internacional de Psicoanálisis, en Zurich, el 17 de julio de 1949. 
fuerte" 13 no tiene que "esmerarse" en producir el poema, sino que el poema nace de necesidades particulares.

En este libro, Bachelard plantea que el poeta está haciendo una sucinta referencia al origen de su cuerpo y su espíritu. Indirectamente, esta idea se asienta en el cuerpo que se percibe, no como una totalidad integrada, sino como algo frágil y efímero. En la poesía de Watanabe, todo ello se precisa en metáforas áureas y volátiles. Es el vínculo que se presenta entre el "estar" y el "ser", y que se asocia con lo corpóreo.

En el aire

hay un latido suave, un pulso que con los años se ha concertado con el mío

Mi casa es membranosa y viva, pero no es asunto uterino. Estoy hablando del lugar de mi cuerpo que he construido, como el pájaro aquel, con baba y donde espacio y función intercambian carne (Watanabe, Lo que queda 82)

Lo que se deslinda del texto parece estar compuesto de un cierto tipo de dramaticidad que evoca las formas de la elocuencia en lo "trágico". El espíritu es rebelde y por lo tanto quiere aparecer ante el otro como fuerte y robusto. La idea proviene de Bachelard, al ofrecernos una serie de pistas profundas que explican el sentido que adquiere el cuerpo en una teoría que parte de los fenómenos naturales. En el poema anterior, Watanabe plantea el texto como si fuera un teorema matemático. Es un teorema suyo, uno que él mismo ha creado. En él están presentes varios elementos de importancia: su casa, su cuerpo, su historia de vida y su historia familiar. La pregunta necesaria aquí es: ¿Qué hace que pensemos en este poema (tanto como en otros, ya que la estructura parece ser común a diversos textos suyos) en un teorema matemático? Nos referimos a la estructura del poema como una construcción perfecta y está planteada como una expresión matemática. En "Mi casa" se nos dan, primero, las hipótesis o axiomas necesarios que requiere todo teorema para que estos sean demostrados; finalmente, nos llega la demostración. 
Para que tengamos una idea más clara de lo que se quiere expresar aquí, veamos primero la definición de teorema matemático. Ernest Nagel y James R. Newman, en su libro El teorema de Gödel, afirman que: "El método axiomático consiste en aceptar sin prueba ciertas proposiciones como axiomas o postulados" (200). Más adelante, ambos también afirman: "Los axiomas constituyen los 'cimientos' del sistema; los teoremas son la 'superestructura', y se obtienen a partir de los axiomas sirviéndose, exclusivamente, de los principios de la lógica" (ibid.). "Mi casa" tiene exactamente esa estructura, tres hipótesis divididas de la siguiente forma: 1) "En el aire/ hay un latido suave"; 2) "un pulso que con los años se ha concertado/ con el mío"; 3 ) "Mi casa es membranosa y viva, pero no es asunto/ uterino". Luego, finalmente, nos otorga la resolución del teorema planteado:
Estoy hablando del lugar de mi cuerpo
que he construido, como el pájaro aquel, con baba
y donde espacio y función intercambian carne (Watanabe, Lo que queda 82)

Volviendo a Bachelard, tenemos que: "La casa es un cuerpo de imágenes que dan al hombre razones o ilusiones de estabilidad" (La poética del espacio 37). Sin embargo, la inmensidad de la que nos habla Bachelard no parece estar presente en el poema de Watanabe. No porque su mundo sea pequeño, sino porque quiere reducirlo a la propia palabra. Quiere hacerlo con la palabra simple y esencial, con la palabra de un provinciano, sin llegar a ser un nativista. De esta manera, jamás intentará minimizarla, sino, al contrario, llevarla a un punto hasta que la palabra se vuelva universal.

De modo que el cuerpo es la palabra y viceversa. Watanabe piensa que el cuerpo del poeta es precisamente ese lugar en el que la escritura juega un papel preponderante, puesto que sin ella él dejaría de existir. Escribir es entenderse con un cuerpo:

claro, se trata de crear un objeto $^{14}$ bello para compartirlo con otros. Y siento que si no lo hago yo no lo va a hacer nadie. Lo digo desde mi propia experiencia, una experiencia muy privada, que no pertenece 
a otro sino a mí. (Rabi do Carmo 98)

y más adelante continúa

Recuerdo que me llamaba y en medio de un corral, entre patos y pollos, trataba de traducirme haikus. Mi padre aprendió bastante bien el castellano e intentaba traducirme algunos haikus. (Rabí do Carmo 103)

La casa como cuerpo es una figura que, al contrario de engrandecerse, se achica y junto con ella también el poeta sufre este pesar. Advirtamos que hemos escrito por separado, casa, poeta y persona, pues Watanabe se nos presenta no como unidad, sino como una tríada. Él divide al hombre del poeta; la poesía surge de una "eventualidad" de su infancia de su tierra natal, Laredo. Probablemente lo haga en el sentido religioso del tema. El poeta siempre está en una escisión, pues el desarraigo se apropia de su destino. No obstante, esta figura no surge de la nada, sino que en casi toda su poesía lo religioso es un punto de encuentro, tal vez debido a la vasta influencia que el padre le provee. En consecuencia, de ningún modo es casual que nos quiera sujetar a la idea de la vasta influencia paterna. La madre, en cambio, aparece siempre de forma más indirecta o no aparece.

En 2002, Watanabe escribe el poemario Habitó entre nosotros. Allí se explora la figura de Jesús en distintas dimensiones, con la intención de verlo en el sentido humano, de describírnoslo en la "quimera" de esta quintaesencia a la que el católico rehúye. En el poema “Oración en Getsemaní” los últimos versos nos dicen:

Entre los olivos, Tú eras el destinatario de tus propias bienaventuranzas pobre de espíritu, hambriento, lloroso, sediento de justicia y con el rumor de una persecución. Tal vez nunca has estado más cerca del Padre. Ya estás en el Padre.

La muerte que se acerca será solo una sangrienta anécdota.

(Watanabe, Poesía 320)

Para él, la religión también es una representación profunda del padre. Lo que hace Watanabe es colocarnos nuevamente en una redención hacia esa 
figura dominante, que funciona como homónimo idéntico a un excelso poeta antiguo, ancestral. El padre le ha enseñado la esencia de la vida y, por ende, la de la palabra. Sin embargo, opera una tesis contraria. Tanto algunos críticos como el propio Watanabe aseguran que lo "ancestral" no es de ninguna manera condición primordial para constituirse en un cuerpo literario, cuanto menos en que su figura sea en sí "el cuerpo". Watanabe piensa que su pensamiento es mucho más ligero de lo que algunos le conceden. Alfredo López-Pasarín Basabe, por ejemplo, nos afirma que: "Parece casi increíble que haya que recordar que Watanabe es un poeta peruano, tan peruano como todos los poetas peruanos que tienen su origen en las más diversas zonas del mundo" (40).

Más bien, la estabilidad y la ilusión son cosas lejanas, el poeta siente una pérdida cuando evoca aquella casa de la infancia a la que ahora quiere referirse. "Mi casa es membranosa y viva, pero no es asunto/ uterino. Estoy hablando del lugar de mi cuerpo" (Watanabe, Lo que queda 82). Es evidente que el poeta está escindido por el sino de lo nefasto, que conlleva lo irremediable. Sin embargo, en la nostalgia de ese pasado que intenta ocultar, recupera algo que ya no está. Reconociéndose en el ahora de su cuerpo, constata a su cuerpo de infante: Afuera soy, como todos, del trabajo y la economía, aquí de mi cuerpo desnudo ( ibid.). Watanabe quiere reafirmarnos que la existencia es un hecho sólido y concreto. Se es solo en cuanto cuerpo, lo demás es un añadido.

Ahora bien, si toda la poesía de Watanabe es intimista, Antígona (2000) es una nueva revelación al mundo de la dramaturgia latinoamericana que se desplaza en dos rutas, una como summum de su propia obra poética, poesía trágica, poesía dramática; otro como nueva perspectiva histórica de la tragedia griega de Sófocles, que resulta aún inusitada para este "nuevo mundo" y no ya el antiguo, el sofocleano. A diferencia de sus otras obras, Watanabe se enfrenta, por primera vez aquí, a la materia poética del teatro y a la rigurosidad de su musicalidad. Aunque ciertos géneros sean más cercanos entre sí -por ejemplo, el teatro de la poesía o la narrativa del cine- la canción a que nos remite la poesía es totalmente diferente de la canción teatral y esto obliga al autor a seguir el camino dramático. El grupo que interpretó por primera vez este texto, el emblemático y ya histórico Yuyachkani, pidió a Watanabe que escribiera un texto para ellos, con motivo de la celebración del Día de la Mujer. Watanabe trajo este drama trágico a la escena. No obstante, el texto mismo posee una peculiaridad: la obra de Watanabe es un poemario, y no, en el sentido estricto de la palabra, un texto escénico. De manera que cada escena es un poema distinto y el diálogo solo está dado de forma individual, en una especie de monólogo interior, o, en todo caso, en reflexión con un otro 
que puede significar un cuerpo vacío, porque está del otro lado, "ausente". Escribir o reescribir esta obra en poesía y no como un teatro tradicional es un hecho que inicialmente responde a que el drama nunca fue un género que Watanabe hubo cultivado. Aunque sí escribió varios guiones para cine y conoció la naturaleza del diálogo, el texto teatral, como se conoce, está por supuesto en otra frontera. Pero este hecho no declina, ni pone en confrontación lo dramático en el texto.

Ahora bien, en la versión del poeta, el tema del cuerpo está presente desde el principio hasta el final. La acción se inicia un día después de la guerra que han librado argivos y tebanos, los primeros con el objetivo de conquistar Tebas y derrocar el poder político controlado por Creonte, y los segundos defendiendo su ciudad que ha estado signada históricamente por males y tragedias. El centro del drama radica en el mito de la dura batalla que Etéocles y Polinices libran ${ }^{15}$ para ver cuál de los dos se queda con el trono de Tebas y la afrenta de Antígona por imponer un acto de sublevación frente a Creonte. Al darse muerte mutuamente, Creonte -tío de Antígona, Ismene, Etéocles y Polinices- decide que el "cuerpo" de Polinices no sea enterrado, sino que sea expuesto a las aves de carroña día y noche, para que el pueblo entienda cuál sería el pago si alguien cometiera traición. Este dictamen acarrea y desencadena una serie de hechos que dan título a la tragedia de Antígona ${ }^{16}$.

La selección de este texto-mito parece ser más que pertinente en Watanabe. Si observamos la continuidad de su obra, percibiremos que el autor peruano indagó desde mucho antes sobre el tema del cuerpo y de lo que para él había significado. Y no solo el cuerpo como interrogante, sino como búsqueda para una poesía que se ubica en medio de la naturaleza, en medio precisamente de una naturaleza áurea. No obstante, en Antígona la mirada ya no está puesta en el lugar natal, ni en la presencia de su "Comala", sino en un principio más amplio: el cuerpo como símbolo del poder y, en sentido opuesto, como símbolo de lucha contra ese poder.

Además, la relación entre cuerpo y sujeto enarbola otra premisa fundamental, que consiste en tener una actitud ética y justa ante un principio básico y vital que no se puede romper: tenemos derecho a nacer y por lo tanto tenemos

15 En algunas versiones se menciona la posibilidad de que Creonte ha urdido el duelo secreto entre Etéocles y Polinices con el objetivo de que se den muerte entre sí y él pueda perpetuarse en el poder.

16 La versión de Sófocles se toma de: Sófocles, Tragedias. Madrid: Gredos, 1981. 
derecho a morir. Aunque parezca un absurdo, el derecho a morir se consuma con el cuerpo enterrado. El no-enterramiento es una no-muerte. Esta acción, que denuesta la condición humana, trae a la reflexión la idea del sujeto y del cuerpo. La inflexión se centra aquí en el rostro. El cuerpo se ve en el rostro, se instala en el rostro como identidad. El cuerpo es una totalidad instituida si se tiene un rostro. No obstante, si no se lo tiene, se pierde la identidad y el cuerpo queda suspendido en medio de una nada.

En Antígona, las referencias al rostro son múltiples y revelan una serie de significaciones, ya no solamente como hecho poético, sino como hecho dramático que invoca a la reflexión y memoria histórica de la actitud que toma el poder contra el hombre. Veamos la lista de versos que describen esta situación:

El día de mi primer mando tuve mi primera felonía:

desapareció la mascarilla mortuoria de Polinices, aquella que hice para que el enemigo tuviera un rostro antes de que bajo el sol, como ordené, perdiera sus facciones. (Watanabe, Antígona 30-31)

Vas mirando sin ansia rostros en las ventanas, árboles, veredas, un brillo de sol en una aldaba, y mil cosas que para ti son últimas (Watanabe, Antígona 39)

Pero Creonte los ha sorprendido. Ha salido al atrio con otro rostro. Nadie sabe si por la razón o el miedo (Watanabe, Antígona 59) ${ }^{17}$

Tal como se desprende de los ejemplos anteriores, el rostro no solo simboliza al mundo interior de cada uno, sino que puede ser unificador del cuerpo como entidad y como esencia de la naturaleza del sujeto. Emmanuel Lévinas ha hecho una larga reflexión en torno al tema del rostro, señalándolo como la representación no de la cosa sino de la subjetividad de la cosa, puesto que "la aparición, en el ser, de esas 'extrañas éticas' -humanidad del hombre- es una ruptura del ser” (Lévinas 73). 
Finalmente, el cuerpo de cualquier sujeto debe estar "libre de toda culpa", es decir, debe estar limpio. Para ello, debe tener un "entierro justo y digno". La exposición del cadáver de Polinices y la progresiva descomposición de su cuerpo, al no ser enterrado, es una referencia expresa a una sociedad (en este caso la peruana) y a un Estado que con su poder omnímodo ejerce sobre los ciudadanos una fuerza irreprimible. Un Estado que, atacando el cuerpo, controló los diferentes estatutos de la vida privada de sus ciudadanos. En efecto, atentando contra el cuerpo del otro se actúa sin objeto de responsabilidad. Por lo tanto, esa responsabilidad no depende del "otro" como cuerpo, sino de que el otro acepte la conjunción de ese marco, o, dicho de otra manera, de que se "responsabilice", aun y cuando no desee dar su consentimiento para ello.

El lazo con el otro no se anuda más que como responsabilidad, de la que no importa que sea aceptada o rechazada, sino que se sepa o no cómo asumirla, que se pueda o no hacer algo concreto por el otro (Lévinas 81).

En la versión de Antígona de Watanabe, Creonte no se siente responsable ni de la muerte de Etéocles, ni de Polinices. Al contrario, juzga en Polinices la responsabilidad de los desastres que ha dejado la guerra ejecutada contra los tebanos. La exposición de un cuerpo, de un cadáver a la vista de todos, de ese cuerpo que muestra sus "blanduras y viscosidades" y que es presa de aves de carroña, es un despropósito, una desvergüenza, una afrenta para lo cual, según Antígona, todos deberíamos reaccionar:

Qué impúdico, qué obsceno

es acabarse insepulto, mostrando

a los ojos de los vivos blanduras y viscosidades. Tal castigo,

y peor, padece mi hermano

porque también es abasto que desgarran alimañas, buitres y perros.

(Watanabe, Antígona 28)

Watanabe halla en la "impureza", en la destrucción natural u obligada del cuerpo, un estado de reflexión para la ética. Se trata de considerar al cuerpo no solo como una entidad portadora de experiencia, sino también de sentido y, particularmente, de sentido histórico. Dando un giro de $180^{\circ}$, Watanabe se ha colocado exactamente en el lugar contrario. Pues no estamos en la reflexión mística individual, en la poesía conversacional de antes, sino en búsqueda del encuentro con un colectivo que históricamente ha sido anulado. 
Acosados por nuestros batallones, corrían por su vida

[aquellos que cantaban

que habían venido a beber nuestra sangre.

No la bebieron y agradezcamos hoy la vida

y el sol

y la paz que es un aire transparente, y empecemos a olvidar.

(Watanabe, Antígona 16)

Estamos ante una voz superior que no tiene "rostro" -en el sentido levinasiano del término-, es decir que no solo no se la puede identificar, sino que esta "a-identidad" nos alerta desde el principio que el cuerpo puede ser, ante todo, el lugar propio de lo desconocido. En términos de Lévinas, es el destino incierto de lo que vendrá.

En Ética e infinito (1991), Lévinas ha puesto de manifiesto el sentido de "encontrarnos en un mundo sin novedades posibles, sin porvenir de la esperanza, un mundo donde todo está regulado de antemano (30). Antígona no se "hace ilusiones", pues ese mundo de oprobios y desencuentros la ha llevado desde su nacimiento a permanecer en la catástrofe y la desventura. En consecuencia, el tema de Antígona no es público sino privado, está en la esfera de lo íntimo, de lo propiamente personal y familiar. Para Antígona, franquear la barrera del poder ejercido por Creonte no es el recurso para organizar una sublevación total y así entroncar al poder plenipotenciario mediante una rebelión. Su frágil cuerpo le impide llevar a cabo la conquista de un grupo de ciudadanos que en número podrían hacer retroceder la dura acción de Creonte, algo que, por lo demás, destruye la tradición histórica representada en su familia.

No será entonces sino en la cueva de la montaña y con su propio suicidio, con la desaparición misma de su cuerpo, que Antígona logre llevar a cabo el enterramiento del cuerpo de su hermano. Atada a una piedra, Antígona se reafirma en la existencia de su ser. No obstante, ello es posible si el cuerpo tiene un sentido. Antígona "es" solo cuando se palpa, cuando su cuerpo se identifica consigo misma y a la vez con el cuerpo del otro:

La oscuridad le da a mi cuerpo una existencia extraña.

Soy

sólo cuando me palpo o toco la dura piedra de la caverna.

Cuando hablo no sé si hablo, acaso sólo sean palabras que circulan sin sonido dentro de mi cabeza. (Watanabe, Antígona 41) 
Al ingresar a la cueva, Antígona ha entrado en el mundo de la caverna, que es el primer paso para avenirse al mundo oscuro de la muerte. Solo mediante esta prueba podrá reconocerse a sí misma. En la ausencia visual de su cuerpo, le queda identificarse por medio de sus sentidos restantes: el tacto, el oído y la voz. Si no me veo, no existo; pero si me palpo y logro identificar mi cuerpo, entonces soy. Simbólicamente, el cuerpo de Antígona será así el cuerpo de un Cristo, pero en sentido inverso: Antígona se convertirá en el cuerpo redimido. No obstante, no lo hace por un cuerpo absoluto que sea capaz de representar la dimensión del pueblo de Tebas y su liberación, sino que su empresa se sustenta en una reivindicación individual, en su familia, su linaje y los que pertenecen a su casta. De los cuatro hermanos, ella es la única que parece sentir culpa de su incestuosa descendencia, pues fue su propia sangre la que manchó su cuerpo, y esto la precipita a tomar acciones y decisiones funestas. Su cuerpo es el centro de su objetivo, "un cuerpo maniatado", que a su vez se autocastiga. Y no ha hecho aquí el poeta peruano ninguna excepción. Su Antígona es la representación más fiel y precisa de la continuidad temática de su obra completa. La versión libre de la Antígona de Watanabe es una referencia constante al cuerpo, al igual que en casi toda su poesía, donde este objeto aparece centrando no solo las temáticas de sus textos, sino también la dirección de su escritura.

La dicotomía entre lo material y lo inmaterial, lo corporal y lo incorpóreo, que históricamente ha atravesado a la poesía en general, es retomada por el poeta peruano en distintos de sus libros. Para Watanabe, lo material no pasa únicamente por el lugar de lo visible. Lo transparente, lo que no se ve, es igual y efectivamente también una materia. De esta forma, lo esencial de su poesía cubre y permea un territorio que nos permite comprender que la palabra poética puede llegar a crear un cuerpo de naturaleza diferente. Esta "otra" materia surge en realidad del cuerpo natural real, del cuerpo visible; y no basta encontrar la esencia de las cosas en el centro de su "existencia", sino en aquello que es sensiblemente vital, en el hallazgo de su "substancia" y su significación.

\section{BIBLIOGRAFÍA}

Adorno, Theodor. Kierkegaard. Construcción de lo estético. Madrid, Akal, 2006.

Bachelard, Gaston. El agua y los sueños. Ciudad de México, Fondo de Cultura Económica, 1978. 
La poética de la ensoñación. Ciudad de México, Fondo de Cultura Económica, 2002.

La poética del espacio. Ciudad de México, Fondo de Cultura Económica, 2012.

Bloom, Harold. La angustia de las influencias. Caracas: Monte Ávila Editores, 1973.

Cevallos Mesones, Leonidas. Los nuevos (Cisneros/Henderson/Hinostroza/Lauer/Martos/ Ortega). Lima: Editorial Universitaria, 1967.

Chirinos, Eduardo. "La poesía peruana en los años sesenta”. Poesía peruana: entre la

fundación de su modernidad y finales del siglo XX. Vol. 4. Giovanna Pollarolo y Luis Fernando Chueca (eds.), 2019, pp. 333-82.

Derrida, JacQues. Resistencias del psicoanálisis. Madrid, Paidós, 1998.

De Lima, Paolo Y Victoria Guerrero. "Grupos poéticos entre 1960 y el 2000: de la Revolución cubana a la hegemonía neoliberal". Historia de las literaturas en el Perú. Vol. 4. Poesía peruana: entre la fundación de su modernidad y finales del siglo XX. Giovanna Pollarollo y Luis Fernando Chueca (coord.). Lima, Casa de la Literatura Peruana, Fondo Editorial de la PUCP y Ministerio de Educación, 2019, pp. 333-381.

Heidegger, Martin. Kant y el problema de la metafísica. Ciudad de México, Fondo de Cultura Económica, 1996.

LACAN, JACQUES. "El estadio del espejo como formador de la función del yo [je] tal como se os revela en la experiencia psicoanalítica". Escritos 1, Ciudad de México, Siglo XXI Editores, 2009, pp. 99-105.

Lao, Fernanda García. "El mal de la vigilia". El País (web), 23 de abril de 2015, consultado el 21 de noviembre de 2021, disponible en: https:/elpais.com/cultura/2015/04/16/ babelia/1429178297_084306.html.

LÉvinas, Emmanuel. Ética e infinito. Madrid, Visor, 1991.

López Parada, Esperanza. "Carne devuelta a la escritura". El País. 22 de mayo de 2004, consultado el 21 de noviembre de 2021, disponible en: https://elpais.com/cultura/2015/04/16/ babelia/1429178297_084306.html.

LóPEZ-PASARÍN BASABE, Alfredo. "Monólogo dramático y construcción semántica en Habitó entre nosotros, de José Watanabe". TRANSMODERNITY: Journal of Peripheral Cultural Production of the Luso-Hispanic World 7, N³, 2017, pp. 39-57.

Maine De Biran, Pierre. Autobiografía y otros escritos. Madrid, Aguilar, 1981.

Nagel, Ernest Y James R. Newman. El teorema de Gödel. Ciudad de México, Centro de Estudios Filosóficos, UNAM,1959.

Nancy, Jean-Luc. El olvido de la filosofía. Madrid, Arena Libros, 2003.

Rabí Do CARmo, Alonso. "El estilo es el lugar donde poso mi alma: una entrevista con José Watanabe”, Quehacer 124, 2000, pp. 98-106.

Real Academia Española. "insondable". Diccionario de la lengua española (web), consultado el 30 de septiembre de 2021, disponible en: https://dle.rae.es/insondable.

Sófocles. Tragedias. Barcelona, Gredos, 1981.

Watanabe, José. Álbum de familia. California, Editorial Ausonia, 1971. 
El huso de la palabra. Lima, Seglusa Editores \& Editorial Colmillo Blanco, 1989. Cosas del cuerpo. Lima, Caballo Rojo, 1999.

Antígona: versión libre de la tragedia de Sófocles. Lima, Yuyachkani, 2000.

Habitó entre nosotros. Lima, Fondo editorial de la Pontificia Universidad Católica del Perú, 2002.

Lo que queda: antología poética (1971-2005). Caracas, Monte Ávila Latinoamericana, 2005.

La piedra alada. Barcelona/Buenos Aires, Pre-Textos/Bajolaluna, 2009.

Poesía completa. Barcelona/Madrid/Buenos Aires, Pre-Textos, 2013.

Yates, Steve. Poéticas del espacio: antología crítica sobre la fotografía. Barcelona, Gustavo Gili, 2002. 